\title{
The economic value of drought information for water management under climate change: a case study in the Ebro basin
}

\author{
S. Quiroga ${ }^{1}$, L. Garrote ${ }^{2}$, A. Iglesias ${ }^{3}$, Z. Fernández-Haddad ${ }^{1}$, J. Schlickenrieder ${ }^{3}$, B. de Lama ${ }^{2}$, C. Mosso ${ }^{4}$, and \\ A. Sánchez-Arcilla ${ }^{4}$ \\ ${ }^{1}$ Department of Statistics, Economic Structure and International Organization, Universidad de Alcala, Spain \\ ${ }^{2}$ Department of Civil Engineering, Universidad Politecnica de Madrid, Spain \\ ${ }^{3}$ Department of Agricultural Economics and Social Sciences, Universidad Politecnica de Madrid, Spain \\ ${ }^{4}$ International Centre for Coastal Research, Universidad Politecnica de Catalunya, Spain
}

Received: 22 June 2010 - Revised: 21 November 2010 - Accepted: 22 November 2010 - Published: 2 March 2011

\begin{abstract}
Drought events in the Mediterranean are likely to increase in frequency, duration and intensity due to climate change, thereby affecting crop production. Information about drought is valuable for river basin authorities and the farmers affected by their decisions. The economic value of this information and the resulting decisions are of interest to these two stakeholder groups and to the information providers. Understanding the dynamics of extreme events, including droughts, in future climate scenarios for the Mediterranean is being improved continuously. This paper analyses the economic value of information on drought events taking into account the risk aversion of water managers. We consider the effects of drought management plans on rice production in the Ebro river basin. This enables us to compute the willingness to compensate the river basin authority for more accurate information allowing for better decision-making. If runoff is reduced, river basin planners can consider the reduction of water allocation for irrigation in order to eliminate the risk of water scarcity. Alternately, river basin planners may decide to maintain water allocation and accept a reduction of water supply reliability, leaving farmers exposed to drought events. These two alternatives offer different risk levels for crop production and farmers' incomes which determine the value of this information to the river basin authority. The information is relevant for the revision of River Basin Management Plans of the Water Framework Directive (WFD) within the context of climate change.
\end{abstract}

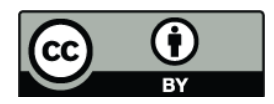

Correspondence to: S. Quiroga

(sonia.quiroga@uah.es)

\section{Introduction}

In the water sector, institutions and users, technology and the economy interact to achieve a balance between water supply and demand in water resource systems. This balance would be maintained if other factors were held constant. However, even if climatic conditions were stationary, the socioeconomic dynamics of the population act as an external driving force moving systems away from equilibrium. Water policy is designed to correct these and other deviations and to allow the system to regain balance between supply and demand of water resources.

Climatic change is an additional external force that should be considered in this continuously adaptive process. There is an agreement in climate projections that there will be a significant reduction of natural runoff in the Mediterranean region, possibly also linked to an intensification of the frequency, duration and magnitude of droughts. The effects of these changes could be devastating in many water resource systems, which are already approaching the limits of sustainability under current climatic conditions.

Water managers must adopt flexible measures to account for climate change in their River Basin Management Plans. When faced with the threat of water scarcity due to climate change, water managers must take into account the uncertainty associated with climate projections. In this paper we analyze the decision-making process of water managers for adaptation to climate change, focusing on the added value provided by climate projections through the concept of risk aversion.

We have selected a simplified decision-making problem: implementing demand reduction measures to adapt system demand to water availability under future climate scenarios.

Published by Copernicus Publications on behalf of the European Geosciences Union. 


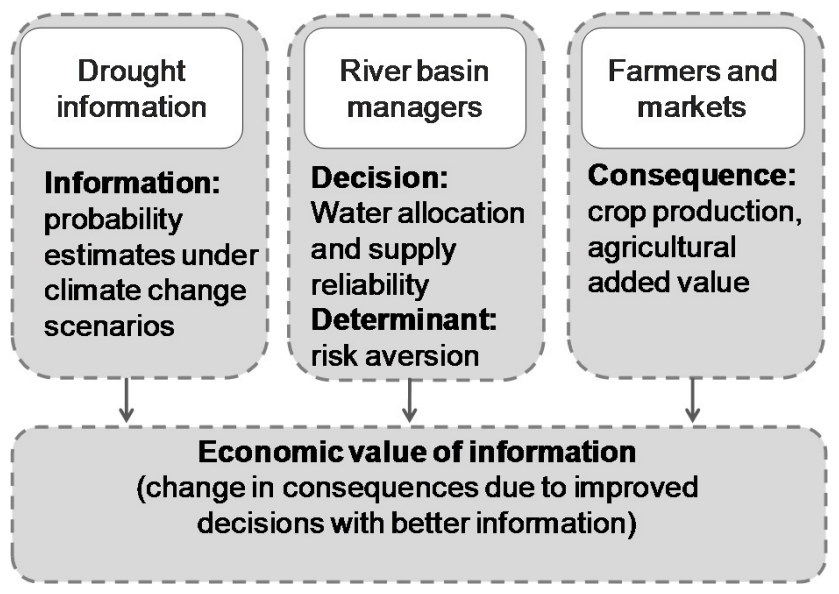

Fig. 1. Steps of methodology.

Traditionally, water managers have designed water resource systems to overcome drought situations. The degree to which droughts produce impacts in water resources systems is analyzed with the help of water resource system models, and depends on the relationship between available resources and demands. System modelers estimate the demand reliability, quantified as the probability that a given demand may suffer water shortages during a given time horizon. This reliability index is normally used for decision making, identifying demands that do not comply with a pre-specified minimum standard. River Basin Management Plans (RBMPs) evaluate the cost and effectiveness of different permanent water conservation or yield enhancement actions for these demands and define a Program of Measures (POM) to correct any reliability deficit. In addition, there are other instruments, such as Drought Management Plans (DMPs) that focus on drought periods and contemplate the temporary water conservation or yield enhancement actions required to overcome a water shortage situation.

Within this framework, if climate projections suggest a reduction of water supplies, water managers must decide whether to apply demand management measures in order to facilitate adaptation to climate change. In this case, demand reduction should focus on economic water uses like irrigation and power production, because essential uses such as environmental flows and urban supply have higher priority and must be maintained. A simplified version of the decisionmaking process faced by water managers is analyzed in this paper. This provides an estimation of the value of information of incorporating considerations of climate change and extreme events into decision-making processes, particularly in the context of river basin management and related plans and programs dealing with water allocation and supply reliability.

\section{Methods}

This paper provides an assessment of the economic value of drought information for water management under climate change applied to rice cultivation in the Ebro basin. First, we provide an overview of climate change information about drought events in the Mediterranean (2.1). This is followed by a description of the climate change adaptation alternatives analysed in this study (2.2), an overview of the case study area (2.3) as well as the Water and Policy Analysis (WAPA) Model applied (2.4). We then discuss the crop production function (2.5), the decision model (2.6) and the calculation of the economic value of information (2.7). Figure 1 outlines the steps of the methodology.

\subsection{Climate change information about drought events in the Mediterranean}

Under all climate change scenarios, water supplies decrease and irrigation demand increases in Spain (Iglesias et al., 2007, 2009). Climate change projections for the region derived from a global climate model driven by socio-economic scenarios (Iglesias et al., 2009) result in an increase of temperature $\left(1.5^{\circ} \mathrm{C}\right.$ to $3.6^{\circ} \mathrm{C}$ in the $\left.2050 \mathrm{~s}\right)$ and precipitation decreases in most of the territory (about 10 to 20 percent decreases, depending on the season). This indicates an increased likelihood of droughts (Kerr, 2005) and variability of precipitation - in time, space, and intensity - that would directly influence water resources availability and river basin management.

Under normal - non drought - conditions, many areas in Spain face significant problems due to the unbalanced distribution of water resources, conflicts among users and between regions. Recurrent drought episodes in the country have led to the intensification of these problems and added to the complexity of water management. Drought events in Spain have been more frequent after 1970 (Iglesias et al., 2007) with economic and social damage increasing from year to year.

Since the runoff output from the GCMs is not adequate for the analysis, a downscaling technique must be applied. Over the last few decades, scientists have developed techniques of regionalization or "downscaling" (dynamic and statistical), in order to translate the climatic variations into results on a regional scale (Khan et al., 2006; Wilby et al., 2004; Vrac et al., 2007; Brekke et al., 2008). Although there is extensive literature on the strengths and weaknesses of the methods of downscaling climatic variables to smaller cells, less attention has been paid to downscaling to examine the impacts of climate change on water resources systems in terms of runoff or groundwater recharge (Fowler et al., 2007; Cayan et al., 2008). Some research (Zhu et al., 2005) employed hydrologic response ratios to translate historical streamflow in a system to streamflow under climate change conditions. Here we follow two approaches to derive the downscaled runoff for the Ebro basin. 
Table 1. Structure of the decision making problem.

\begin{tabular}{lll}
\hline & \multicolumn{2}{c}{ State of Nature } \\
\hline Action & $\begin{array}{l}\text { Occurrence of extreme event } \\
\text { (drought years) }(\theta=1)\end{array}$ & $\begin{array}{l}\text { No extreme event } \\
\text { (non-drought years) }(\theta=0)\end{array}$ \\
\hline $\begin{array}{l}\text { Maintain water allocation for agriculture, } \\
\text { accepting a reduction of supply reliability }\end{array}$ & $\begin{array}{l}\text { Production loss due to }(-L) \\
\text { the occurrence of a drought event }\end{array}$ & No production loss $(0)$ \\
\hline $\begin{array}{l}\text { Reduce water allocation for agriculture } \\
\text { to obtain adequate supply reliability }\end{array}$ & $\begin{array}{l}\text { Production loss due to the reduction of } \\
\text { water allocated for irrigation: }(-\gamma L)\end{array}$ & $\begin{array}{l}\text { Production loss due to the reduction of } \\
\text { water allocated for irrigation: }(-\gamma L)\end{array}$ \\
\hline
\end{tabular}

\subsection{Climate change adaptation measures}

Water resources system models can be useful tools to study the effects of climate change and to identify adaptation strategies in the water sector. Climate change scenario projections for the Ebro basin imply that current agricultural water demands cannot be satisfactorily met.

In order to analyze the vulnerability of the system, we need to estimate the evolution of water demand expected in the system during the selected scenarios (period 2071-2100). Then, in order to evaluate system performance and aid in the planning and management decision process, two management options can help to analyze impact, vulnerability and potential adaptation to projected climate change. Several authors have proposed different indices to condense the results of water resources system management models. Reliability describes how likely a system is to fail (Hashimoto et al., 1982a, b; El-Baroudy and Simonovic, 2004). Reservoir regulation has been one of the most important water resources management strategies in Spain in recent years and has generated significant impacts. The management of water allocation to reduce the disparity between water supply and demand has to take into account changes on water supply reliability.

Drought events are a key factor determining water supply and reliability, since under drought conditions water systems reduce normal conditions and the probability of the system failing increases. Therefore, drought occurrence is an important factor to consider when designing water management plans.

In adapting to a possible reduction of water supplies in water systems, we have considered two different alternatives: the first considers maintaining water allocation for agriculture, thereby reducing supply reliability and the second considers a reduction in water allocation for agriculture, thereby increasing supply reliability. The hypotheses are further described below (Table 1):

Alternative 1: maintain current water allocation for agriculture. Under this alternative, the quantity of water assigned for irrigation is maintained, but the probability of the system failing is higher in the case of runoff shortages. So, in this case, in future climate scenarios supply reliability will be reduced, and farmers will be exposed to water scarcity during drought years. In normal years (no drought), agricultural production will be maintained at the current level, and there will be no net loss. In drought years, there will be water shortages, and agricultural production will be reduced accordingly. If $Y$ is average crop yield for current water allocation in normal years, average crop yield during drought years will be a fraction of $Y, \mathrm{k} Y$, with $\mathrm{k}<1$. Under the occurrence of a drought event, farmers will take a production loss, L, equal to:

$L=Y-k Y=(1-k) Y$

In this case, farmers cannot implement adaptation measures such as reducing cultivated land or changing crops as possible responses to reduce the impact of water shortages. This is because under this alternative, it is assumed that water shortage cannot be anticipated and the system fails to respond to an extreme event (drought). The yield loss for Alternative 1 is therefore higher.

The probability of having water shortages in any given year, $P_{\theta}$, is computed with the help of a water resource system simulation model and is given by the supply reliability of agricultural demand, $\mathrm{R}$ :

$R=\frac{N_{a}}{N_{t}}$

where $N_{a}$ is the number of years in the simulation with acceptable water supply and $N_{t}$ is the total number of years.

$P_{\theta}$ will be $: P_{\theta}=1-R$

Alternative 2: reduce water allocation for agriculture, in order to obtain satisfactory water supply reliability. If runoff is reduced, the probability of the system failing will increase unless water allocated to agriculture is reduced, thereby increasing the disparity between water supply and demand but allowing the demand to anticipate the shortage (this implies less water but with greater reliability). In this case, farmers will not be exposed to water scarcity during drought years, 


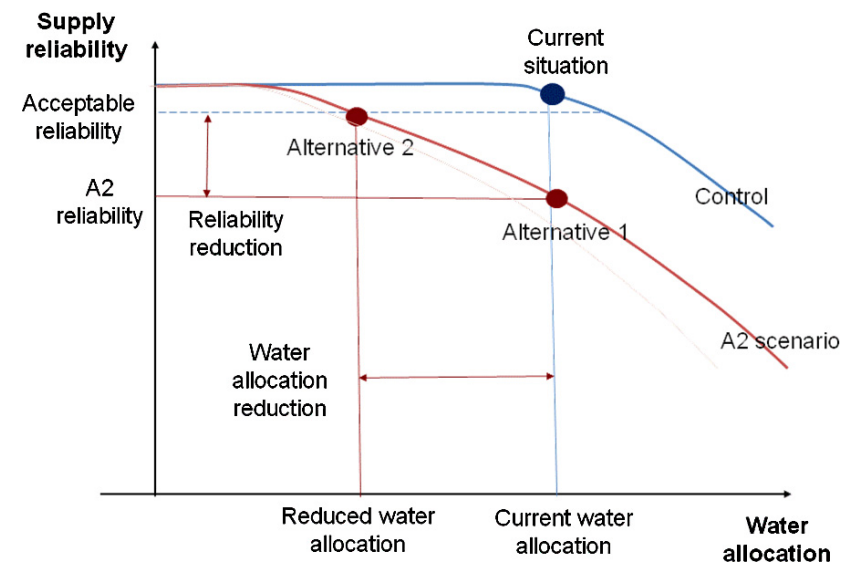

Fig. 2. Example of demand-reliability analysis in a basin for a given climate change scenario.

because the water supply system will be able to overcome the drought situation. However, the reduction of water allocation implies a production loss every year. If $\beta$ is the reduction of water allocation, the yield in normal and drought years will be $\beta \alpha Y$, where $\alpha$ is the production sensitivity to water availability. Therefore, the net loss taken by farmers would be:

$Y-\alpha \beta Y=(1-\alpha \beta) Y$

This loss can be expressed as a fraction $\gamma$ of the loss taken under alternative one: $\gamma \mathrm{L}$, with coefficient $\gamma$ equal to:

$\gamma=\frac{(1-\alpha \beta)}{(1-k)}$

In Alternative 2, farmers are assumed to attempt to adapt to the reduced water availability, which ensures that the yield loss is less than in Alternative 1. However, this loss is permanent and not associated to a particular extreme event, but rather, to a change in the normal conditions.

Quantitative parameters for the decision problem can be obtained from the demand-reliability curve, which is obtained by computing the evolution of reliability as the demand value changes. For instance, Fig. 2 presents an example of demand-reliability analysis in a basin for a given climate change scenario. Under the control (current) scenario, the demand-reliability curve provides reliability for current water allocation in the basin, which is above the acceptable threshold. Under the climate change scenario (A2), the demand reliability curve changes. If water allocation is maintained at current level, demand reliability would be lowered to A2 reliability, below the acceptable threshold. If the system manager wants to maintain reliability at least at the acceptable threshold, water allocation has to be reduced accordingly.

\subsection{Description of the case study}

Our study focuses on the Ebro river basin. The Ebro basin, located in the northeast of the Iberian Peninsula, is the largest basin in Spain, with an area of $85000 \mathrm{~km}^{2}$ and a mean annual runoff of $16.92 \mathrm{~km}^{3} \mathrm{yr}^{-1}$. It currently supplies water to 2700000 people and around 800000 ha of irrigated land. Urban supply and consumptive industrial demand is $0.96 \mathrm{~km}^{3} \mathrm{yr}^{-1}$ and irrigation demand is $6.32 \mathrm{~km}^{3} \mathrm{yr}^{-1}$.

To illustrate the loss of production generated from differences in the management of water systems, we analyse rice production, one of the main agricultural crops of the Ebro delta (60\% of its surface). Rice production in this region plays a crucial role in the economy and ecology of the Ebro estuary and was chosen because of its dependence on water for irrigation. The total production of rice is about 120,000 metric tonnes per year, the third most important crop of the European Union. An extensive irrigation system delivers fresh water from the Ebro River to the rice fields. In addition to the grain harvest, rice fields play a significant ecological role in the over-wintering of migratory birds (Martínez-Vilalta, 1995; Ibáñez, 2000; Forés, 1989). Although our analysis uses rice cultivation as an example, we have not modelled water for rice production specifically and we assume that reductions of water allocation are equally distributed between different crops.

\subsection{Water Availability and Policy Analysis (WAPA) Model}

Quantitative parameter values for the formulation of the decision problem were obtained using WAPA (Water Availability and Policy Analysis), a simplified water resources simulation model applied to the Ebro basin.

WAPA was used to compute the demand-reliability (DR) curve, providing a simple way to evaluate water availability under different climate change scenarios. WAPA simulates the joint operation of all reservoirs in a basin to satisfy a unique set of demands. Basic inputs to the WAPA model are the river network topology, the reservoir characteristics (monthly maximum and minimum capacity, storagearea relationship and monthly evaporation rates), the naturalized stream flow series entering different points of the river network, the environmental flow conditions downstream of reservoirs and monthly values of urban and agricultural demands for the entire basin. The model is based on the mass conservation equation, and the main assumptions refer to how reservoirs are managed in the system: To supply demands any given month, water is preferentially taken from the most downstream reservoir available, since spills from upstream reservoirs can be stored in downstream ones. In each time step, the model performs the following operations: 
Table 2. Climate change runoff projections for the Ebro basin (CEDEX).

\begin{tabular}{llllr}
\hline $\begin{array}{l}\text { Scenario } \\
\text { name }\end{array}$ & $\begin{array}{l}\text { Emission } \\
\text { Scenario }\end{array}$ & $\begin{array}{l}\text { GCM } \\
\text { model }\end{array}$ & $\begin{array}{l}\text { Downscaling } \\
\text { method }^{(1)}\end{array}$ & $\begin{array}{r}\text { Runoff } \\
\text { change \% }\end{array}$ \\
\hline CB & B2 & CGCM2 & Statistical method 1 & -4 \\
EB & B2 & ECHAM4 & Statistical method 1 & -25 \\
HB & B2 & HadAM3 & Statistical method 1 & -9 \\
SB & B2 & HadCM3 & Statistical method 2 & -11 \\
UB & B2 & ECHAM4 & SMHI & -17 \\
PB & B2 & HadCM3 & UCM & -29 \\
Average B & B2 & & & -16 \\
CA & A2 & CGCM2 & Statistical method 1 & -17 \\
EA & A2 & ECHAM4 & Statistical method 1 & -31 \\
HA & A2 & HadAM3 & Statistical method 1 & +3 \\
SA & A2 & HadCM3 & Statistical method 2 & -40 \\
UA & A2 & ECHAM4 & SMHI & -30 \\
PA & A2 & HadCM3 & UCM & -46 \\
Average A & A2 & & & -28 \\
\hline
\end{tabular}

(1) Statistical method 1 and 2: Statisitcal dowscalling by CEDEX (MARM, 2006); SMHI: Swedish Meteorological and Hydrological Institute downscalling; UCM: Uniersidad Complutense de Madrid.

1. Satisfaction of the environmental flow requirement in every reservoir with the available inflow. Environmental flows are passed to downstream reservoirs and added to their inflows.

2. Computation of evaporation in every reservoir and reduction of available storage accordingly

3. Increment of storage with the remaining inflow, if any. Computation of excess storage (storage above maximum capacity) in every reservoir.

4. Satisfaction of demands in order of priority, if possible. Use of excess storage first, then available storage starting from higher priority reservoirs.

5. If excess storage remains in any reservoir, computation of uncontrolled spills.

The result of the joint reservoir operation model is a set of time series of monthly volumes supplied to each demand and monthly values of stored volume, spills, environmental flows and evaporation losses in every reservoir. Reliability is computed for every demand by comparing the actual supply values with theoretical demand values during the simulation. A macro is available to repeat the computations' changing values of a given demand type, which allows the computation of the demand-realiability curve.

The WAPA model was applied to the Ebro basin system composed of 34 rivers, 27 major reservoirs totaling $7.13 \mathrm{~km}^{3}$ of reservoir storage, an urban demand of $0.96 \mathrm{~km}^{3} \mathrm{yr}^{-1}$ and current irrigation demand of $6.35 \mathrm{~km}^{3} \mathrm{yr}^{-1}$. Naturalized monthly streamflow series are available for 47 points in the river network for the period 1940-1996. This data set was assumed to correspond to the control situation. Climate change scenarios were generated for every streamflow point in the Ebro basin by transforming the mean and coefficient of variation of the original series as suggested by the corresponding climate projection. Environmental flows were fixed at $10 \%$ of mean annual flow in every location.

Climate change in the Ebro basin is characterised from downscaled global change scenarios obtained from the Prudence project (PRUDENCE, 2007, Christensen and Christensen, 2007; Fronzek and Carter, 2007) and from the Spanish National Adaptation Plan (MARM 2006). Tables 2 and 3 show how downscaled scenarios were derived in this study. The socio-economic scenarios used are A2 and B2 (IPCC SRES, 2001) and define socio-economic conditions and the greenhouse gas emission levels that are used to derive projected climate change impacts in the GCMs. Since no single projection is a prediction, scenarios represent alternative futures. Here we use 23 climate change scenarios constructed as a combination of four Global Climate Models (Had CM3, Had AM3, ECHAM4, CGCM2) downscaled for Europe with 11 Regional Climate Models and downscaled for the Iberian Peninsula with one Regional Climate Model and two methods of statistical downscaling (Tables 2 and 3). Runoff data from climate scenarios was obtained directly from the Prudence project for the scenarios included in Table 3. These results, which vary in resolution from $50 \mathrm{kms}$ to $22 \mathrm{kms}$, are publicly available on the web page http://prudence.dmi.dk/. Runoff data from the Spanish National Adaptation Plan scenarios (Table 2) was obtained modifying the observed streamflow series (period 1967-1990) with monthly changes 
Table 3. Climate change runoff projections in the Ebro basin taken from PRUDENCE project.

\begin{tabular}{llllrr}
\hline Scenario name & $\begin{array}{l}\text { Emission } \\
\text { Scenario }\end{array}$ & $\begin{array}{l}\text { GCM } \\
\text { model }\end{array}$ & $\begin{array}{l}\text { Downscaling } \\
\text { method }\end{array}$ & $\begin{array}{r}\text { Runoff change } \\
\text { Mean } \%\end{array}$ & $\begin{array}{r}\text { Runoff change } \\
\text { Coeff.Var. \% }\end{array}$ \\
\hline DMI1-A & A2 & HadCM3 & DMI & -28 & -11 \\
DMI2-A & A2 & HadCM3 & DMI & -35 & -28 \\
DMI3-A & A2 & HadCM3 & DMI & -39 & -2 \\
ETH-A & A2 & HadCM3 & ETH & -45 & +58 \\
GKSS-A & A2 & HadCM3 & GKSS & -31 & +19 \\
ICTP-A & A2 & HadCM3 & ICTP & +28 & +2 \\
KNMI-A & A2 & HadCM3 & KNMI & -46 & +38 \\
MPI-A & A2 & HadCM3 & MPI & -42 & +6 \\
SMHI & A2 & HadCM3 & SMHI & -33 & +31 \\
UCM-A & A2 & HadCM3 & UCM & -36 & +72 \\
PRUD-A & A2 & & & -31 & +18 \\
\hline
\end{tabular}

(1) Statistical method 1 and 2: Statisitcal dowscalling by CEDEX (MARM, 2006); SMHI: Swedish Meteorological and Hydrological Institute downscalling; UCM: Uniersidad Complutense de Madrid.

of hydrological variables computed for the baseline period and the 2050s decade. The analysis was conducted by the CEDEX (Center of Studies and Experimentation of Public Works of the Spanish Ministry of the Environment, Rural Affairs and Marine Affairs, MARM, 2006).

A fixed value of $0.96 \mathrm{~km}^{3} \mathrm{yr}^{-1}$ of urban demand and a variable irrigation demand was considered in order to obtain the demand-reliability curve for irrigation demand. Priority was given to urban demand over irrigation demand. The reliability measure applied to compute the demand-reliability curve was:

$R^{k}=100 \frac{N_{\mathrm{a}}^{k}}{N_{\text {tot }}}$

where, $R^{k}$ is time reliability in percentage, $N_{\mathrm{a}}^{k}$ is the number of years with acceptable water supply (years where total supply is above a given threshold, $k$ ), and $N_{\text {tot }}$ is the total number of years. A threshold of $98 \%$ of total demand was selected as an acceptable supply in any given year.

\subsection{Crop production functions of yield response}

Statistical models of yield response have proven useful to evaluate the effects of extreme events such as drought, frost or floods (Dixon et al., 1994; Moss and Shonkwiler, 1993; Chavas et al., 2001; Lobell et al., 2005, 2007). Statistical models of yield response have been used to evaluate the sensitivity and adaptation to climate, e.g., in Spain (Iglesias et al., 2000) and globally (Parry et al., 2004; Stanger et al., 2008), and can be used to estimate the risk associated with climate variability (Ferreyra et al., 2001; Iglesias and Quiroga, 2007) with potential applications in crop insurance (Luo et al., 1994).
In order to determine the effects of water management on yield variability, a multiple linear regression model was estimated by ordinary least squares (OLS) using climatic data as explanatory variables. To consider the effect of technical progress, we have incorporated several management indicators as input variables. (Quiroga and Iglesias, 2009; Iglesias and Quiroga, 2007). Observed annual rice production data (1976-2002) at the province level were obtained for the provinces on the Ebro river basin, from the Statistical Division of the Spanish Ministry of Agriculture (MAPA, 2010).

The specified model has the general form:

$$
\begin{aligned}
& \ln Y_{t}=\alpha_{0}+\alpha_{1} \ln \mathrm{Mac}_{t} \\
& +\alpha_{2} \ln \text { NitroFer }_{t}+\alpha_{3}{\ln \text { Irrig }_{t}} \\
& +\alpha_{4} \ln _{\operatorname{Tavg}}+\alpha_{4} \operatorname{Prec}_{t} \\
& +\alpha_{5} \ln \mathrm{Fr}_{t}+\alpha_{6} \mathrm{Dro}_{t}+\varepsilon_{t}
\end{aligned}
$$

where the dependent variable $Y_{t}$ is the crop yield in a site in the year $t$, and the explanatory variables are described on Table 4.

Recurrent drought periods affect agricultural production. Drought characterisation is difficult due to its spatial and temporal properties and consequently a range of indicators are used (Hayes, 2004; Keyantash and Dracup, 2002; Bradford, 2000). We opted for the commonly used Standardised Precipitation Index (SPI, McKee et al., 1993). The SPI calculates the difference of accumulated precipitation between a selected aggregation period and the average precipitation for that same period. For its calculation, the precipitation record is normalized so that all precipitation values vary around 0 and areas with different climates can be relatively compared (McKee et al., 1993; Steinmann et al., 2003). We have selected 12 months as the aggregated period for calculation and defined the threshold of drought as values of SPI smaller than 
Table 4. Description of the variables in the crop production function.

\begin{tabular}{llll}
\hline Name & Definition & Units & Source of Data \\
\hline $\mathrm{Y}_{t}$ & Crop yield at a site in year $\mathrm{t}$ & $\mathrm{t} / \mathrm{ha}$ & MARM (Spanish ministry for \\
\hline $\mathrm{Mac}_{t}$ & Technification of the crop production in year $\mathrm{t}$ & $\begin{array}{l}\mathrm{N}^{\circ} \text { of agrarian } \\
\text { machinery }\end{array}$ & $\begin{array}{l}\text { FAO (Food and agriculture organization) } \\
\text { agriculture and the environment) }\end{array}$ \\
\hline Nitro_fer $_{t}$ & Nitrogenized fertilizers & $\mathrm{Qm}$ & FAO \\
\hline $\mathrm{Irrig}_{t}$ & Net water needs of crops in the ith month in year $\mathrm{t}$ & $\mathrm{mm}$ & CHEBRO (Ebro river basin authority) \\
\hline $\mathrm{T} \_\mathrm{Av}_{t}$ & Average temperature in the agricultural year $\mathrm{t}$ & ${ }^{\circ} \mathrm{C}$ & AEMET(Meteorological Spanish Service) \\
\hline $\mathrm{Prec}_{t}$ & $\begin{array}{l}\text { Total precipitation in the ith month/ } \\
3 \text { month period in year t }\end{array}$ & $\mathrm{mm}$ & AEMET \\
\hline $\mathrm{Fr}_{t}$ & $\begin{array}{l}\text { No. of days with temperatures below } \\
0{ }^{\circ} \mathrm{C} \text { in the agricultural year t }\end{array}$ & days & AEMET \\
\hline Dro $_{t}$ & $\begin{array}{l}\text { Dummy variable for drought } \\
\text { years based on SPI index }\end{array}$ & 0 or 1 & $\begin{array}{l}\text { Own elaboration from } \\
\text { precipitation data AEMET }\end{array}$ \\
\hline
\end{tabular}

-1 , following previous detailed work in Spain (Iglesias et al., 2007; Garrote et al., 2006). Then, a dummy variable has been constructed that equals 1 if the year $\mathrm{t}$ is a drought year (with SPI smaller than -1 ) and 0 in the rest of the cases.

To build a proxy variable for irrigation, we used data on net crop water requirements from the Ebro basin management authority (CHEBRO, 2004). Given that currently there are no explicit restrictions on the irrigated area in the Ebro basin, we assume that water requirements of crops are being met. As we mentioned before, this is likely due to runoff reductions projected under climate change.

Coefficients were estimated by OLS from the observed time series (1976-2002). In order to improve the particular model estimation for each crop, 95\% confidence intervals were estimated assuming normality of the residuals, and significant relations in the estimated model were considered. Akaike (1973) and Schwarz (1978) criteria have been used to assist in the selection of suitable models. The Ljung-Box $\mathrm{Q}$ test - based on the autocorrelation plot - was used to test the absence of autocorrelation in the residuals, and White's general test (White, 1980) was used to test conditional heteroscedasticity.

When the parameters $\alpha_{i}$ are estimated, the marginal effect of a change in the explanatory variables is given by:

$$
\frac{\partial E\left[\ln Y \mid \ln X_{i}\right]}{\partial \ln X_{i}}=\alpha_{i}
$$

The signs and magnitude of the marginal effects indicate the effect of a particular input variable $X_{i}$ over the crop yield and the interpretation is: It is the elasticity that is the percent increase of yields produced by a one percent increase in the input variable.

\subsection{Decision model and risk aversion}

A decision model is a mathematical formulation of the consequences associated with all combinations of a set of actions and a set of possible states of the world. The likelihoods of the states of the world are represented by probabilities. If information is to have value, the decision rule will differ depending on the information received by the decision maker. (Meza et al., 2003). More details about the economic theory and valuation of information can be found in Johnson and Holt (1986).

Our decision making problem has the same structure as that of the more general cost-loss ratio situation problem also widely known as the "umbrella problem". The cost-loss ratio situation is a decision-making problem widely analyzed in the literature assessing the economic value of weather forecasts (e.g., Murphy, 1977; Murphy et al., 1985, Murphy and Ehrendorfer, 1987; Katz, 1993; Palmer, 2002; Katz and Ehrendorfer, 2006). The model involves two possible actions, protect, and not protect, and two possible events, adverse weather, and no adverse weather. The decision maker is assumed to incur a cost $\mathrm{C}$ if protective action is taken, and a loss $\mathrm{L}$ if protective action is not taken and adverse weather occurs, and no cost or loss otherwise. An expected value approach has been commonly used.

However, results highly depend on agents' behaviour with respect to risk. Most of the studies consider agents to be neutral towards risk, but there is evidence of risk aversion under most situations. Therefore, in order to use this methodology to evaluate the value of weather information it is necessary to know: (i) information on the expenses matrix, (ii) climate information (probability of the extreme event) and, (iii) information about the risk aversion level. Assuming that the 
consequences of each combination of actions and state of the world are known a priori, the model allows for the representation of the decision maker's preferences (i.e. utilities associated with the future outcomes), and sets a decision rule by which an optimal strategy is selected once the expected utility of each decision is calculated (Meza et al., 2003).

In Cerdá and Quiroga (2010) a model is proposed to evaluate information considering the risk aversion level. The main concept used for this purpose is the certain equivalent. The certain equivalent (CE) can be defined as the amount of money producing the same utility $(\mathrm{U})$ without uncertainty as the expected utility (EU) of a gamble when the risk exists. The role of risk aversion is analyzed here by considering that a manager decides between Alternative 1 (more risk) and Alternative 2 (less risk).

In order to evaluate risk influence on managers' decisions - and therefore obtain the value of information - we analyze the decision considering the risk aversion, which is one of the central concepts in economic analysis (Mas-Colell et al., 1995). We assume that manager preferences can be represented by the expected utility with the utility function $U(-)$, the CARA function (Constant Absolute Risk Aversion) (Mas-Colell et al., 1995), being:

$U(x)=-\exp \{-\rho x\}$

where: $x$ is the monetary gain and $\rho>0$ is the Arrow-Pratt coefficient of absolute risk aversion, which is constant for this function.

The Arrow-Pratt absolute risk aversion coefficient can be interpreted as the percentage change in marginal utility caused by each monetary unit of a gain or loss (Raskin and Cochran, 1986). If the coefficient does not change across the monetary level, the decision-maker exhibits constant absolute risk aversion (CARA), which implies that the level of the argument of the utility function does not affect his or her decisions under uncertainty. Since $\rho$ is not a non-dimensional measure of risk aversion, its value is dependent on the currency in which the monetary units are expressed (GómezLimón et al., 2003), which makes comparison between different economic agents difficult. However, it remains a good measure for decision- making problems involving one sole economic agent. This is suitable for the river basin manager's decision problem, while the risk aversion remains independent of the productivity loss value. The optimal decision in this case is obtained maximizing the expected utility, which increases with the decrease of the expected yields reduction. (This is the reason for writing the payoffs as negative monetary costs).

As in Cerdá and Quiroga (2010), we consider the incorporation of additional information to the model. It is introduced as an imperfect weather forecasting. The goal is to obtain the optimal decision rule but also to quantify the economic value of a forecasting system, considering the information value as the benefit of changing the farmer's behaviour when he or she has access to additional information. Let the random variable

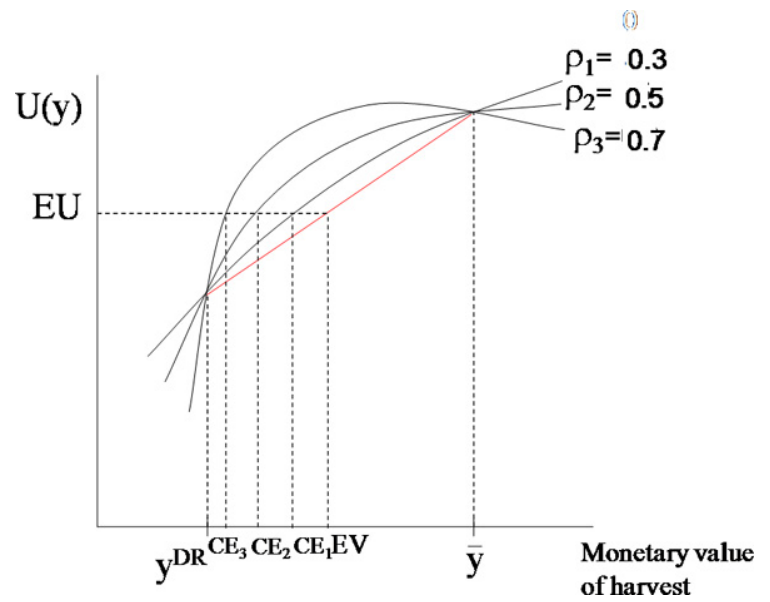

Fig. 3. Expected value (EV), expected utility (EU) and certain equivalent (CE) and sensitivity analysis to risk aversion.

$Z$ which indicates a forecast of adverse weather $(Z=1)$, or of non adverse weather $(Z=0)$ be introduced. As in Murphy et al. (1985) it is assumed that $\operatorname{Pr}\{Z=1\}=\operatorname{Pr}\{\theta=1\}=P_{\theta}$, that is, the forecasting system produces adverse weather signals with the same probability that adverse weather events take place, so the forecast is at least as accurate as information based just on the historical records. The quality of information is defined in terms of the following index:

$q=\operatorname{Corr}(\theta, Z)=\frac{\left(P_{1}-P_{\theta}\right)}{\left(1-P_{\theta}\right)}$, where $P_{1}=\operatorname{Pr}\{\theta=1 / Z=1\}$

Table 5 summarizes the variables introduced in the model and the source of information for the case study considered.

\subsection{Computing the economic value}

In order to achieve a monetary value unchanging with linear utility transformations in order to compute the amount of money that farmers will pay for the forecast service, we have considered the certainty equivalence approach. The certain equivalent (CE) can be defined as the amount of money for which the farmer is indifferent between the gamble and the certain amount CE (Mas-Colell et al., 1995), that is the amount of money producing the same utility without uncertainty as the expected utility when the risk exists (See Fig. 3).

The certain equivalent allows us to define a value of information in monetary terms. Then, it is possible to compare the value of information between the risk-averse and risk-neutral cases, and also to compare different agents. Cerdá and Quiroga (2010) define the monetary gains (MG), as the difference in certainty equivalent due to the introduction of forecasting information, that is: $\mathrm{MG}=\mathrm{CEF}$ (with forecasting)CENF (without forecasting) and compute the monetary gains of an information system. For the decision problem with risk, defined in Table 1, the optimal decision of the manager considering the maximization of the expected utility criterion is: 
Table 5. Description of the variables included in the decision making model.

\begin{tabular}{|c|c|c|}
\hline Name & Variable & Source of information \\
\hline$\theta$ & $\begin{array}{l}\text { Extreme event variable }(\theta=1, \\
\text { "drought event"; } \quad \theta=0 \text {, "no } \\
\text { drought event" }\end{array}$ & SPI calculation \\
\hline$K$ & $\begin{array}{l}\text { Reduction coefficient for produc- } \\
\text { tion during drought years }\end{array}$ & $\begin{array}{l}\text { Crop production } \\
\text { functions }\end{array}$ \\
\hline$L=Y-(K \cdot Y)=(1-K) Y$ & $\begin{array}{l}\text { Loss when the demand is main- } \\
\text { tained during the drought event } \\
\text { happens (therefore the guarantee } \\
\text { is reduced) }\end{array}$ & $\begin{array}{l}\text { Crop production } \\
\text { functions }\end{array}$ \\
\hline$\beta$ & $\begin{array}{l}\text { Reduction coefficient for water } \\
\text { demand }\end{array}$ & WAPA simulations \\
\hline$\alpha$ & $\begin{array}{l}\text { Yield elasticity to irrigation water } \\
\text { availability }\end{array}$ & $\begin{array}{l}\text { Crop production } \\
\text { functions }\end{array}$ \\
\hline$C$ & $\begin{array}{l}\text { Loss when the water for irrigation } \\
\text { is reduced. \% of the loss when } \\
\text { the guaranty is reduced: } C=Y- \\
(\alpha \beta Y)=(1-\alpha \beta) Y=\gamma L\end{array}$ & $\begin{array}{l}\text { WAPA simulations } \\
\text { and crop production } \\
\text { functions }\end{array}$ \\
\hline$\rho$ & $\begin{array}{l}\text { Arrow-Prat absolute risk aversion } \\
\text { coefficient }\end{array}$ & $\begin{array}{l}\text { Calibration based on } \\
\text { Gómez-Limón et al, } \\
2003\end{array}$ \\
\hline$P_{\theta}$ & Climate information: $\operatorname{Pr}[\theta=1]$ & WAPA simulations \\
\hline$q$ & $\begin{array}{l}\text { Forecast quality: } \operatorname{Corr}(\theta, Z) \\
\text { where } Z \text { represents imperfect } \\
\text { forecast variable }(Z=1 \text {, "ad- } \\
\text { verse weather"; } Z=0 \text {, "non } \\
\text { adverse weather") }\end{array}$ & Sensitivity analysis \\
\hline
\end{tabular}

i. Alternative 1 if $A>P_{\theta}$, and in this case the expected utility is $\operatorname{EU}(0)=-P_{\theta} \exp \{\rho L\}+P_{\theta}-1$

ii. Alternative 2 if $A<P_{\theta}$, and the expected utility is $\operatorname{EU}(1)=-\exp \{\rho \gamma L\}$

iii. Indifference between both alternatives if $A=P_{\theta}$

where $A=\frac{1-\exp \{\rho \gamma L\}}{1-\exp \{\rho L\}}$.

The monetary gain of a forecast defined as the difference between CEF and CENF can be computed as:

$\operatorname{MG}(q)$

$=\frac{\ln \left[P_{\theta} \exp \{\rho \gamma L\}+\left(1-P_{\theta}\right)-P_{\theta}(1-\exp \{\rho L\})\left[1-q\left(1-P_{\theta}\right)+P_{\theta}\right]\right]}{-\rho}$

$+\gamma L$

if $0 \leq A \leq P_{\theta}$, and

$\operatorname{MG}(q)$ $=\frac{\ln \left[\frac{P_{\theta} \exp \{\rho \gamma L\}+\left(1-P_{\theta}\right)-P_{\theta}(1-\exp \{\rho L\})\left[1-q\left(1-P_{\theta}\right)-P_{\theta}\right]}{1-P_{\theta}(1-\exp \{\rho L\})}\right]}{-\rho}$,

if $A>P_{\theta}$.

The economic value of the forecast system can be expressed as a function of the quality index. There is a threshold, $q_{A}^{*}=1-\frac{A}{P_{\theta}}$, below which the forecast system does not improve the farmer's expected utility, that is, the economic value is positive if and only if $q>q_{A}^{*}$. This threshold increases with the absolute risk aversion coefficient of ArrowPratt $\rho$. So, with a more risk-adverse agent the information quality needed to influence his decision making is higher.

Although individuals' risk tolerance varies, we assume that $\rho=0.5$ represents the risk aversion coefficient. PalaciosHuerta (2003) suggested that $\rho$ typically ranges from 0.3 to 0.7 , centred on 0.5 . So, using the WAPA simulations and the production functions results, we have calculated the monetary gains or economic value of the extremes information systems. 
Table 6. Summary of results from the WAPA model.

\begin{tabular}{|c|c|c|c|c|c|c|c|}
\hline Projection & $\begin{array}{r}\text { Mean annual } \\
\text { runoff }\left(\mathrm{km}^{3} \mathrm{yr}^{-1}\right)\end{array}$ & $\begin{array}{l}\text { Change in mean } \\
\text { annual runoff }(\%)\end{array}$ & $\begin{array}{l}\text { Change in coef.var. } \\
\text { annual runoff }(\%)\end{array}$ & $\begin{array}{l}\text { Irrigation demand for } 98 \% \\
\text { reliability }\left(\mathrm{km}^{3} \mathrm{yr}^{-1}\right)\end{array}$ & $\begin{array}{l}\text { Required reduction of } \\
\text { of irrigation } \\
\text { demand } \beta\end{array}$ & $\begin{array}{c}\text { Reliability for } \\
\text { current irrigation } \\
\text { demand }(\%)\end{array}$ & $\begin{array}{c}\text { Probability } \\
\text { water shortage } \\
\text { for current } \\
\text { irrigation demand } \mathrm{P}_{\theta}\end{array}$ \\
\hline $\mathrm{CB}$ & 16.25 & -4 & 0 & 6.35 & 0.00 & 98 & 0.02 \\
\hline EB & 12.69 & -25 & 0 & 5.38 & 0.15 & 80 & 0.20 \\
\hline HB & 15.40 & -9 & 0 & 6.12 & 0.03 & 95 & 0.05 \\
\hline SB & 15.06 & -11 & 0 & 6.12 & 0.03 & 95 & 0.05 \\
\hline UB & 14.05 & -17 & 0 & 5.78 & 0.09 & 88 & 0.13 \\
\hline PB & 12.01 & -29 & 0 & 5.17 & 0.18 & 77 & 0.23 \\
\hline AverageB & 14.21 & -16 & 0 & 5.86 & 0.07 & 88 & 0.13 \\
\hline $\mathrm{CA}$ & 14.05 & -17 & 0 & 5.78 & 0.09 & 88 & 0.13 \\
\hline EA & 11.68 & -31 & 0 & 5.11 & 0.19 & 71 & 0.29 \\
\hline HA & 17.43 & 3 & 0 & 6.71 & 0.00 & 98 & 0.02 \\
\hline SA & 10.15 & -40 & 0 & 4.52 & 0.28 & 52 & 0.48 \\
\hline UA & 11.85 & -30 & 0 & 5.08 & 0.20 & 71 & 0.29 \\
\hline $\mathrm{PA}$ & 9.14 & -46 & 0 & 4.06 & 0.36 & 41 & 0.59 \\
\hline AverageA & 12.18 & -28 & 0 & 5.25 & 0.17 & 77 & 0.23 \\
\hline DMI1-A & 12.18 & -28 & -11 & 5.50 & 0.13 & 80 & 0.20 \\
\hline DMI2-A & 11.00 & -35 & -28 & 5.42 & 0.14 & 70 & 0.30 \\
\hline DMI3-A & 10.32 & -39 & -2 & 4.61 & 0.27 & 54 & 0.46 \\
\hline ETH-A & 9.31 & -45 & 58 & 2.67 & 0.58 & 43 & 0.57 \\
\hline GKSS-A & 11.68 & -31 & 19 & 4.41 & 0.30 & 64 & 0.36 \\
\hline ICTP-A & 21.66 & 28 & 2 & 7.70 & 0.00 & 100 & 0.00 \\
\hline KNMI-A & 9.14 & -46 & 38 & 3.15 & 0.50 & 41 & 0.59 \\
\hline MPI-A & 9.81 & -42 & 6 & 4.14 & 0.34 & 48 & 0.52 \\
\hline SMHI-A & 11.34 & -33 & 31 & 3.80 & 0.40 & 59 & 0.41 \\
\hline UCM-A & 10.83 & -36 & 72 & 2.72 & 0.57 & 54 & 0.46 \\
\hline PRU-A & 11.68 & -31 & 18 & 4.41 & 0.30 & 64 & 0.36 \\
\hline
\end{tabular}

Table 7. Descriptive statistics (mean, min, max, range and standard deviation) of the variables used in the crop yield regression equation.

\begin{tabular}{llllll}
\hline Variable & Mean & Min & Max & Range & Std. Dev. \\
\hline $\mathrm{Y}_{t}$ & 5.4 & 3.0 & 7.3 & 4.3 & 1.0 \\
Mac $_{t}$ & 697225.0 & 400928.0 & 946053.0 & 545125.0 & 156327.3 \\
Nitro_fer $_{t}$ & 987587.6 & 788072.0 & 1199000.0 & 410928.0 & 132714.3 \\
Irrig $_{t}$ & 1326.3 & 565.9 & 2145.1 & 1579.2 & 669.5 \\
T_Av $_{t}$ & 15.4 & 13.9 & 16.9 & 3.0 & 0.8 \\
Prec $_{t}$ & 430.5 & 180.1 & 770.0 & 589.9 & 130.3 \\
Fr $_{t}$ & 2.1 & 0.1 & 5.3 & 5.3 & 1.5 \\
\hline
\end{tabular}

\section{Results}

\subsection{Water allocation reductions and water reliability trade-off}

The results obtained are presented in Fig. 4 and in Table 6 . Figure 4 presents the demand-reliability curves of irrigation demand, once urban demand has been satisfied, for current conditions and for average projections AverageB, AverageA and PRU-A. Desired reliability (98\%) is represented as a horizontal dashed line. Intersections of this line with the demand reliability curves in climate change projections correspond to the maximum irrigation demand values that are allowed to maintain the desired reliability. Current demand $\left(6.32 \mathrm{~km}^{3} \mathrm{yr}^{-1}\right)$ is represented as a vertical line. Intersec- tions of this line with the demand reliability curves in climate change projections correspond to the reliabilities that would be obtained if irrigation demand was left unchanged. Numerical values for all projections are presented in Table 6 .

\subsection{Water effects on irrigated agricultural production}

Table 7 illustrates the descriptive statistics (mean, min, max, range and standard deviation) of the variables used in the crop yield regression equation and Table 8 shows the result of the statistical function of yield response to water. The coefficients of the model can be interpreted as direct elasticities since the model presents a logarithmic transformation except for the drought effects. So, the estimated coefficients represent the proportional changes on the dependent 
Table 8. Estimated coefficients of the crop production function for rice production.

\begin{tabular}{lrr}
\hline & $\ln _{-} \mathrm{Y}_{t}$ & t-statistic \\
\hline $\ln _{-} \mathrm{Mac}_{t}$ & 0.7389 & {$[3.47]^{* * *}$} \\
$\ln _{-}$Nitro_fer $_{t}$ & -0.2308 & {$[1.11]$} \\
$\ln _{-}$Irrig $_{t}$ & 0.1067 & {$[2.27]^{* *}$} \\
$\ln _{-} \mathrm{Fr}_{t}$ & -0.0674 & {$[2.25]^{* *}$} \\
Dro $t$ & -0.1454 & {$[2.25]^{* *}$} \\
Constant & -5.8483 & {$[2.33]^{* *}$} \\
R-squared & 0.53 & \\
Observations & 42 & \\
$\mathrm{~F}(5,36)$ & 8.23 & \\
Prob $>\mathrm{F}$ & 0.0000 & \\
\hline
\end{tabular}

Robust t statistics in brackets. * significant at $10 \% ; * *$ significant at $5 \%$; *** significant at $1 \%$

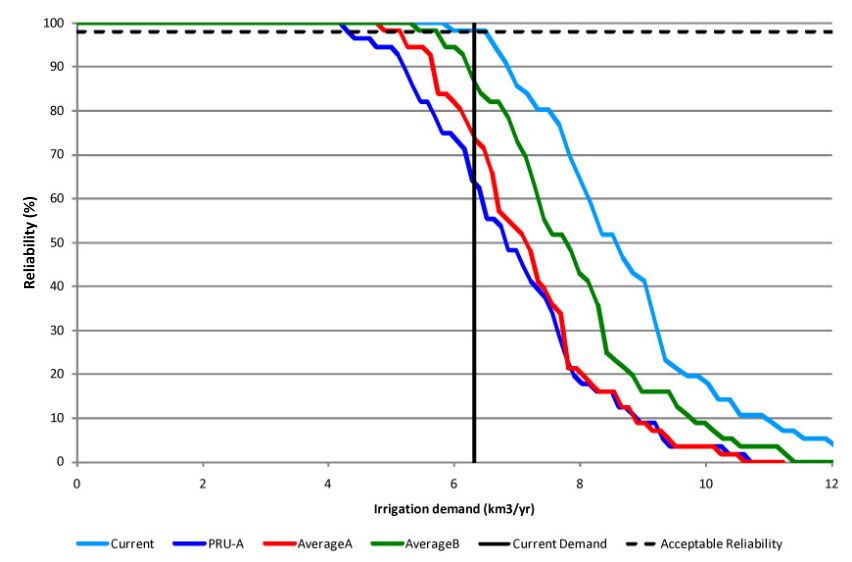

Fig. 4. Demand reliability curves for current conditions and for climate projections Average B (Average for B2 scenario), Average A (average for A2 scenario) and PRU-A (average of Prudence models for A2 scenario).

variable, when a $1 \%$ change is produced on the explanatory variable associated to this coefficient. The drought variable coefficient can be interpreted as semi-elasticity and represents the percent variation of yield when drought occurs. Due to the presence of heteroskedasticity, we used the White test (1980) to obtain robust estimates. Technological change is represented by farm machinery results in yield increases for rice production. This variable is the main driver of productivity. Then, irrigation also has a positive impact, so reductions in water availability for irrigation will result in a decrease of yields. The water output elasticity is 0.10 , which indicates that a decrease of $1 \%$ in water for irrigation will lead to a decrease of more than $10 \%$ in the crop yield. This reduction is not so high, but it is important to notice that during drought events, a reduction of more than $14 \%$ has to be added (since the elasticity of drought is 0.14 ). The Ebro

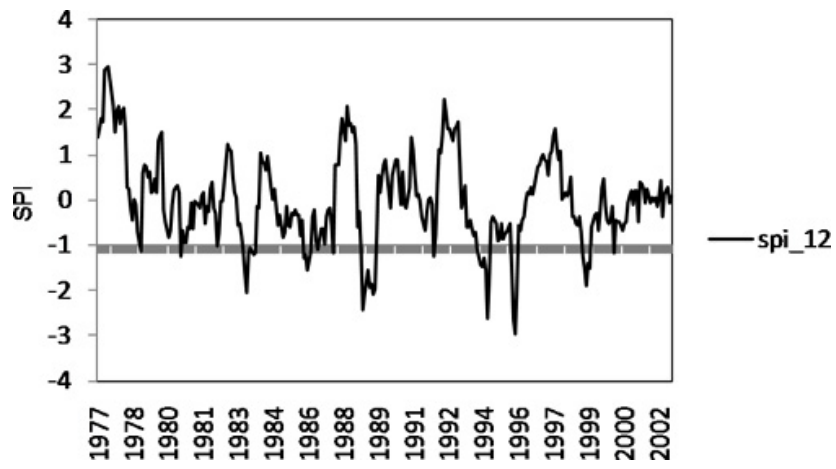

Fig. 5. SPI and drought periods for Tarragona in the Ebro river basin (1977-2002).

Basin is located in the Northeast of the Iberian Peninsula with a primarily Continental Mediterranean climate, characterized by hot-dry summers and cold-wet winters. Up to the present, there have been no explicit restrictions on the irrigation area in the Ebro basin. However, in a climate change context with more drought events and the water framework directive environmental restrictions, the scene could be very different.

Drought has a considerable negative effect. Agriculture in Spain is more sensitive to inter-annual rainfall variations than many other European regions because the physical factors affecting production (soils, terrain, and climate) are, in large areas, less suited to farming. Drought pseudo-elasticity $(K)$ is estimated to be -0.14 . Figure 5 shows the SPI and the drought periods considered (those bellow -1 ). Since rice is an irrigated crop, irrigation may go up during droughts masking the effects of drought itself.

\subsection{Selecting water management options}

The payoff matrix for each of the scenarios considered was calculated from the WAPA simulations and the crop production functions. Table 9 shows an example of the decisionmaking problem under the Prudence-A scenario. Reduction of water allocation acts as a non-risk option (similar to insurance), since the farmers know by how much the water allocation is going to be reduced. This reduction takes place independently of the existence of drought. On the other hand, if there is no change in the water allocated, the probability of system failure increases in the case of an extreme event (drought). This results in farmers having less water available and it eliminates the possibility of anticipating the event because it is a failure of the system. If drought does not occur, the system will not fail and farmers won't suffer water shortages, in which case no losses are incurred.

In Spain, water allocation means assigning a given annual amount of water to a certain demand. It is, in fact, awarding a right to use water, which is done by the Water Administration, in the form of an administrative concession. 
Table 9. Payoff matrix (reduction of rice yield) for Prudence-A scenario.

\begin{tabular}{lll}
\hline Action & $\begin{array}{l}\text { Occurrence of extreme event } \\
\text { (drought years) } \\
(\theta=1)\end{array}$ & $\begin{array}{l}\text { No extreme event } \\
\text { (non-drought years) } \\
(\theta=0)\end{array}$ \\
\hline $\begin{array}{l}\text { Reduction of water allocation for agri- } \\
\text { culture }\end{array}$ & $\begin{array}{l}\text { Production loss due to the reduction of } \\
\text { water allocated for irrigation } \\
-0.41 \%\end{array}$ & $\begin{array}{l}\text { Production loss due to the reduction of } \\
\text { water allocated for irrigation } \\
-0.41 \%\end{array}$ \\
\hline
\end{tabular}

No change in the water allocation for $\begin{aligned} & \text { Production loss due to the occurrence of } \\ & \text { No production loss } 0 \% \\ & \text { agriculture leading to a reduction of wa- }\end{aligned}$ ter reliability

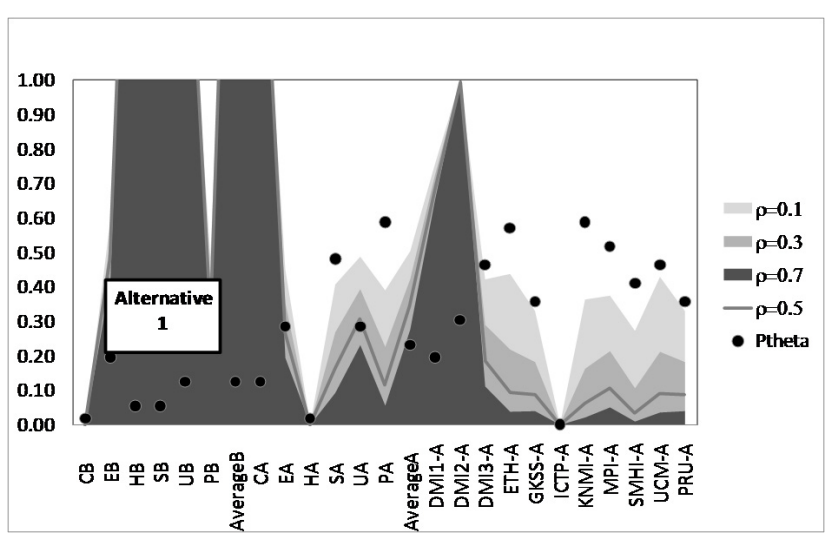

Fig. 6. Optimal policy regions.

Water allocation is then revised periodically in River Basin Management Plans, based on the estimation of available supplies. Water reliability refers to the average number of years with adequate supply for the water currently allocated to that demand. If runoff is reduced due to climate change and there is no change in water allocation, the same demand has to be supplied with less resources, and one can expect an increased frequency of shortage situations which leads to a reduction in reliability. If water allocation is reduced, reliability can be maintained, because there would be less consumption every year. In this case, agriculture would probably get less water overall, but the supply would be more reliable.

The optimal policy was calculated as described in Sect. 2.6. Figure 6 shows the optimal policy regions with the corresponding trade-off between supply and reliability. For the scenarios in which the black points $P_{\theta}$ are in the white area, Alternative 2 (reducing the water allocated for irrigation) is the optimal decision, independently of the risk aversion coefficient considered. On the other hand, for the scenarios in which the $P_{\theta}$ is in the dark grey area, Alternative 1 (reducing water reliability) is the optimal decision. Reducing

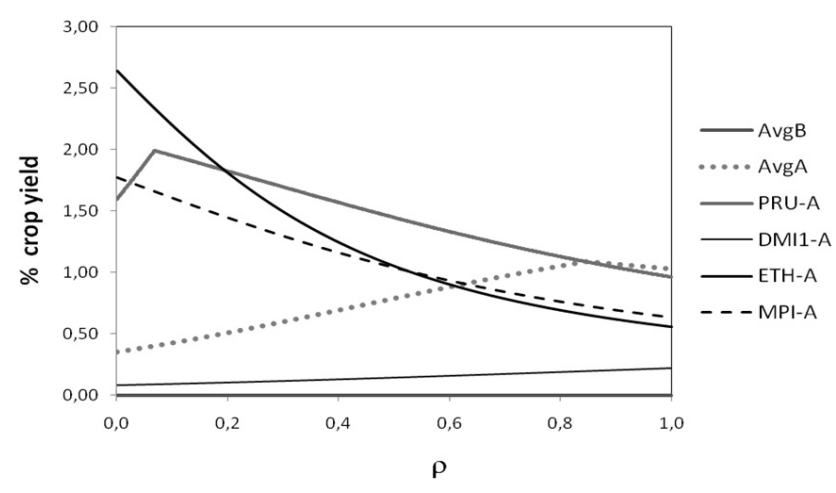

Fig. 7. Economic value of perfect information as a function of the risk aversion coefficient.

water allocation has a lower associated risk level, and would therefore be preferred by managers that are more risk averse (dark grey). Reducing water reliability has a higher associated risk level and would therefore be preferred by those less risk averse (light grey) (Fig. 6). The results show that there is no optimal policy response and that this is highly dependent on the scenario considered. This is indicative of the importance and relevance of climate change information.

\subsection{Economic value of drought information}

In Fig. 7 we present the economic value of perfect information as a function of the risk aversion coefficient of the water management authority and for each of the climate change scenarios analysed. Perfect information assumes that quality of the prevision is one $(q=1)$ and can be understood as the maximum information accuracy.

Each climate change scenario is associated with a different estimated probability of drought, and as we have seen in Sect. 3.3, this probability determines the optimal management decision. In cases in which the decision-maker changes 
his/her mind as a consequence of the climate information which occurs in the scenarios shown in Fig. 7 - a different loss of production results as a consequence of the change in the decision. This difference in lost production can be interpreted as the economic value of information in providing accurate climate change and extreme event projections in decision-making processes.

Based on our analysis in the Ebro River Basin, we observed that the provision of information on streamflow forecasts could compensate losses of production of more than $2 \%$, as illustrated in the difference in crop yield change between the highest and lowest case scenario. This can be used as a low limit of the value of providing improved information and projections of climate change and extreme events. Considering that this information can provide considerable benefits to society, public investment in research and the provisioning of relevant and timely information is likely to be justified. The risk aversion of the management authority plays an essential role, since the more risk aversion, the less the value of the climate information.

The avoided losses have been estimated for rice production. An interesting continuation of the study would be to estimate the impacts on other crops in the basin to see if there are important differences in the avoided losses.

\section{Conclusions}

Information on the likely impact of climate change on river basins and its provision to the stakeholders and river basin management authorities will be valuable in facilitating adaptation and in achieving public awareness and acceptance of decisions that are made. If runoff is reduced under climate change, river basin plans could reduce water allocation for irrigation and thereby eliminate the risk of water scarcity or maintain water allocation and accept a reduction of water supply reliability, The value of information and therefore, of informed decision making, to river basin authorities is the difference between the risk to farmers' incomes with versus without the information. This can be used as an indicator to quantify the overall threat as an important factor for consideration in the cyclical 6 year review process of the River Basin Management plans.

This study identifies the benefits of weather, climate and water information in the agricultural sector as called for in the Madrid Conference Statement and Action Plan of the World Meteorological Organisation. This will aid in guiding policy-making in river basins and determining economic public investments in research and institutions that can provide information to facilitate adaptation for farmers and other stakeholders in the face of climate change extremes.

Acknowledgements. This research has been supported by the European Commission CIRCE project and the ARCO project of the Spanish Ministry of Environment, Rural, and Marine Affairs (MARM).
Edited by: U. Ulbrich

Reviewed by: G. Rossi and another anonymous referee

\section{References}

Akaike, H.: A maximum likelihood estimation of Gaussian autoregressive moving average models, Biometrika, 60, 255-265, 1973.

Bradford, R. B.: Drought events in Europe, in: Drought and drought mitigation in Europe, edited by: Vogt, J. V. and Somma, F., Kluwer Academic Drodrecht, 7-20, 2000.

Brekke, L.D., Dettinger, M. D., Maurer, E. P., and Anderson, M.: Significance of model credibility in estimating climate projection distributions for regional hydroclimatological risk assessments, Climatic Change, 89, 371-394, 2008.

Cayan, D.R., Maurer, E. P., Dettinger, M. D., Tyree, M., and Hayhoe, K.: Climate change scenarios for the California region, Climatic Change, 87, (Suppl 1): S21-S42, 2008.

Cerdá, E. and Quiroga, S.: Economic value of weather forecasting: the role of risk aversion, TOP: An Official Journal of the Spanish Society of Statistics and Operations Research, in press, doi:10.1007/s11750-009-0014-3, 2010.

Chavas, J., Kim, K., Lauer, J., Klemme, R., and Bland, W.: An economic analysis of corn yield corn profitability and risk at the edge of the Corn Belt, J. Agr. Resour. Econ., 26(1), 230-247, 2001.

CHEBRO (Confederación Hidrogrfica del Ebro): Revisin de las Necesidades Hdricas Netas de los Cultivos en la Cuenca del Ebro, 1961-2002, Zaragoza, Spain, 2004.

Christensen, J. H. and Christensen, O. B.: A summary of the PRUDENCE model projections of changes in European climate by the end of this century, Climatic Change, 81, 7-30, 2007.

Dixon, B. L., Hollinger, S. E., Garcia, P., and Tirapattur, V.: Estimating corn yield response models to predict impacts of climate change, J. Agr. Resour. Econ., 19(1), 58-68, 1994.

El-Baroudy, I. and Simonovic, S. P.: Fuzzy criteria for the evaluation of water resource systems performance, Water Resour. Res., 40, W10503, doi:10.1029/2003WR002828, 2004.

Ferreyra, R. A, Podestá, G. P., Messina, C. D., Lestón, D., Dardanelli, J., Guevara, E. and Meira, S.: A linked-modeling framework to estimate maize production risk associated with ENSOrelated climate variability in Argentina, Agr. Forest Meteorol., 107 pp, 177-192, 2001.

Forés, E.: Ricefields as filters, Arch. Hydrobiol., 116 pp., 517-527, 1989.

Fowler, H. J., Blenkinsop, S., and Tebaldi, C.: Linking climate change modeling to impacts studies: Recent advances in downscaling techniques for hydrological modeling, Int. J. Climatol., 27, 1547-1578, 2007.

Fronzek, S. and Carter, T.: Assessing uncertainties in climate change impacts on resource potential for Europe based on projections from RCMs and GCMs, Climatic Change, 81, 357-371, 2007.

Garrote, L., Flores, F., and Iglesias, A.: Linking Drought Indicators to Policy Actions in the Tagus Basin Drought Management Plan, Water Resour. Manage., 21, 873-882, 2007.

Gómez-Limón, J. A., Arriaza, M., and Riesgo, L.: An MCDM analysis of agricultural risk aversion, Eur. J. Oper. Res., 151, 569$585,2003$. 
Hashimoto, T., Stedinger, J. R., and Loucks, D. P.: Reliability, resiliency, and vulnerability criteria for water resources system performance evaluation, Water Resour. Res., 18, 14-20, 1982a.

Hayes, M. J.: Drought indexes, National Drought Mitigation Center, Nebraska, USA, http://drought.unl.edu/whatis/indices.htm, 2004.

Ibáñez, C.: Integrated management in the special protection area of the Ebro Delta: implications of rice cultivation for birds, Proceedings of the Conference on the Council Directive on the Conservation of Wild Birds, European Commission, 98-103, 2000.

Iglesias, A. and Quiroga, S.: Measuring the risk of climate variability to cereal production at five sites in Spain, Climate Res., 34, 45-57, 2007.

Iglesias, A., Rosenzweig, C., and Pereira, D.: Agricultural impacts of climate in Spain: developing tools for a spatial analysis, Global Environ. Chang., 10, 69-80, 2000.

Iglesias, A., Garrote, L., Flores, F., and Moneo, M.: Challenges to manage the risk of water scarcity and climate change in the Mediterranean, Water Resour. Manag., 21(5), 227-288, 2007.

Iglesias, A., Cancelliere, A., Cubillo, F., Garrote, L., and Wilhite, D. A.(eds): Coping with drought risk in agriculture and water supply systems: drought management and policy development in the Mediterranean, Springer, The Netherlands, 320 pp., 2009.

Johnson, S. R. and Holt, M. T.: The value of climate information, in: Policy Aspects of Climate Forecasting, Krasnow, R., Resources for the future, 53-78, 1986.

Katz, R. W. and Ehrendorfer, M.: Bayesian approach to decision making using Ensemble weather forecasts, Weather Forecast., 21, 220-231, 2006.

Katz, R. W.: Dynamic cost-loss ratio decision making model with an autocorrelated climate variable, J. Climate, 5, 151-160, 1993,

Kerr, R. A.: Confronting the Bogeyman of the climate system, Science, 310, 432-433, 2005.

Keyantash, J. and Dracup, J. A.: The quantification of drought. An evaluation of drought indices, B. Am. Meteorol. Soc., 83, no. 8 (Aug) 1167-1180, 2002.

Khan, M. S., Coulibaly, P., and Dibike, Y.: Uncertainty analysis of statistical downscaling methods, J. Hydrol., 319, 357-382, 2006.

Lobell, D. B., Ortiz-Monasterio, J. I., Asner, G. P., Naylor, R., Falcon, W., and Matson, P.: Analysis of wheat yield and climatic trends in Mexico, Field Crop. Res., 94 (2-3), 250-256, 2005.

Lobell, D. B., Ortiz-Monasterio, J. I., and Falcon, W. P.: Yield uncertainty at the field scale evaluated with multi-year satellite data, Agr. Syst., 92, 76-90, 2007.

Luo, H., Skees, J. R., and Marchant, M. A.: Weather information and the potential for the inter-temporal adverse selection in crop insurance, Rev. Agr. Econ., 16, 441-451, 1994.

MAPA: Anuarios de estadstica agroalimentaria, years: 1940 to 2000, Ministry of Agriculture, Statistical Division, Madrid, http: //www.mapa.es/es/estadistica/pags/anuario/introduccion.htm, 2010.

MARM: Plan Nacional de Adaptación al Cambio Climático (PNACC), Ministerio de Medio Ambiente y Medio Rural y Marino - Madrid, Spain, http://www.mma.es/portal/secciones/ cambio_climatico/areas_tematicas/impactos_cc/pdf/pna_v3.pdf accessed 10 October 2010, 2006.

Martínez-Vilalta, A.: The rice fields of the Ebro Delta, in: Management of Mediterranean Wetlands, edited by: C. Morillo and J. L. González, Ministerio de Medio Ambiente, Madrid, 1995.
Mas-Colell, A., Whinston, M. D., and Green, J. R.: Choice under uncertainty, Microeconomic Theory, Chapter 6, 167-197, Oxford University Press, New York, 167-197, 1995.

McKee, T. B., Doesken, N. J., and Kleist, J.: The relationship of drought frequency and duration to time scales, 8th Conference on Applied Climatology, Anaheim, CA, UISA, 1993.

Meza, F. J., Wilks, D. S., Rihab, S. J., and Stedingerc, J. R.: Value of perfect forecasts of sea surface temperature anomalies for selected rain-fed agricultural locations of Chile, Agr. Forest Meteorol., 116, 3-4, 7-135, 2003.

Moss, C. B. and Shonkwiler, J. S.: Estimating yield distributions with a stochastic trend and nonnormal errors, Am. J. Agr. Econ., 75, 1056-1062, 1993.

Murphy, A. H.: The value of climatological, categorical and probabilistic forecasts in the cost-loss ratio situation, Mon. Weather Rev., 105, 803-816, 1977.

Murphy, A. H. and Ehrendorfer, M.: On the Relationship between the accuracy and value of forecasts in the Cost-Loss ratio situation, Weather Forecast., 2, 243-251, 1987.

Murphy, A. H., Katz, R. W., Winkler, R. L., and Hsu, W.: Repetitive decision making and the value of forecasts in the cost-loss ratio situation: a dynamic model, Mon. Weather Rev., 113, 801-813, 1985.

Palacios-Huerta, I.: An empirical analysis of the risk properties of human capital returns, Am. Econ. Rev., 93(3), 948-964, 2003.

Palmer, T. N.: The economic value of Ensemble forecasts as a tool for risk assessment: from days to decades, Q. J. Roy. Meteor. Soc., 128, 747-774, 2002.

Parry, M. A., Rosenzweig, C., Iglesias, A., Livermore, M., and Fischer, G.: Effects of climate change on global food production under SRES emissions and socio-economic scenarios, Global Environ. Chang., 14, 53-67, 2004.

PRUDENCE(Prediction of Regional scenarios and Uncertainties for Defining European Climate change risk and Effects) http: //prudence.dmi.dk/, 2007.

Quiroga, S. and Iglesias, A.: A comparison of the climate risks of cereal, citrus, grapevine and olive production in Spain, Agr. Syst., 101, 91-100, 2009.

Raskin, R. and Cochran, M. J.: Interpretations and transformations of scale for the Pratt-Arrow absolute risk aversion coefficient: Implications for generalized stochastic dominance, Western J. Agr. Econ., 11(2), 204-210, 1986.

Schwarz, G.: Estimating the dimension of a model, Ann. Stat., 6, 461-464, 1978.

Stanger, T. F., Lauer, J. G., and Chavas, J. P.: The profitability and risk of Long-term cropping systems featuring different rotations and Nitrogen rates, Agron. J., 100, 105-113, 2008.

Steinmann, A.: Drought indicators and triggers: a stochastic approach to evaluation, J. Am. Water Resour. Assoc., 39, 12171233, 2003.

Vrac, M., Stein, M. L., Hayhoe, K., and Liang, X.-Z.:A general method for validating statistical downscaling methods under future climate change, Geophys. Res. Lett., 34, L18701, doi:10.1029/2007GL030295, 2007.

White, H.: A heteroscedasticity-consistent covariance matrix estimator and a direct test for heteroscedasticity, Econometrica, 48, 817-838, 1980. 
Wilby, R. L., Charles, S. P., Zorita, E., Timbal, B., Whetton, P., and Mearns, L. O.: Guidelines for use of climate scenarios developed from statistical downscaling methods, Supporting material of the Intergovernmental Panel on Climate Change, available from the DDC of IPCC TGCIA, 27, 2004.
Zhu, C., Lee, W., Kang, H., and Park, C.: A proper monsoon index for seasonal and inter-annual variations of the East Asian monsoon, Geophys. Res. Lett., 32, L02811, doi:10.1029/2004GL021295, 2005. 